Pacific Journal of Mathematics

ON THE RESULTANT HYPERSURFACE 


\title{
ON THE RESULTANT HYPERSURFACE
}

\author{
A. D. R. ChOUdARY
}

The resultant $R(f, g)$ of two polynomials $f$ and $g$ is an irreducible polynomial such that $R(f, g)=0$ if and only if the equations $f=0$ and $g=0$ have one common root.

When $g=f^{\prime} / p$, then $D(f)=R(f, g)$ is called the discriminant of $f$ and the discriminant hypersurface $D_{p}=\left\{f \in \mathbf{C}^{p}, D(f)=0\right\}$ can be identified to the discriminant of a versal deformation of the simple hypersurface singularity $A_{p-1}: x^{p}=0$. In particular, the fundamental group $\pi=\pi_{1}\left(\mathbf{C}^{p} \backslash D_{p}\right)$ is the famous braid group and $\mathbf{C}^{p} \backslash D_{p}$ in fact a $K(\pi, 1)$ space.

Here we prove the following.

TheOREM. $\pi_{1}\left(\mathbf{C}^{p+q} \backslash R_{p, q}\right)=Z$.

As $\mathrm{C}^{p} \backslash D_{p}$ can be regarded as a linear section of $\mathrm{C}^{p+q} \backslash R_{p, q}$, this theorem shows that by a nongeneric linear section the fundamental group may change drastically, in contrast with the case of generic section.

Let $f=x^{p}+a_{1} x^{p-1}+\cdots+a_{p}$ and $g=x^{q}+b_{1} x^{q-1}+\cdots+b_{q}$ be two monic polynomials with complex coefficients of degree $p$ and $q$ respectively.

The resultant of them $R(f, g)$ is an irreducible polynomial in the coefficients $a_{i}, b_{j}$ such that $R(f, g)=0$ if and only if the equations $f=0$ and $g=0$ have at least one common root. Explicitly, the resultant is given by the next formula (see for instance [5], p. 136):

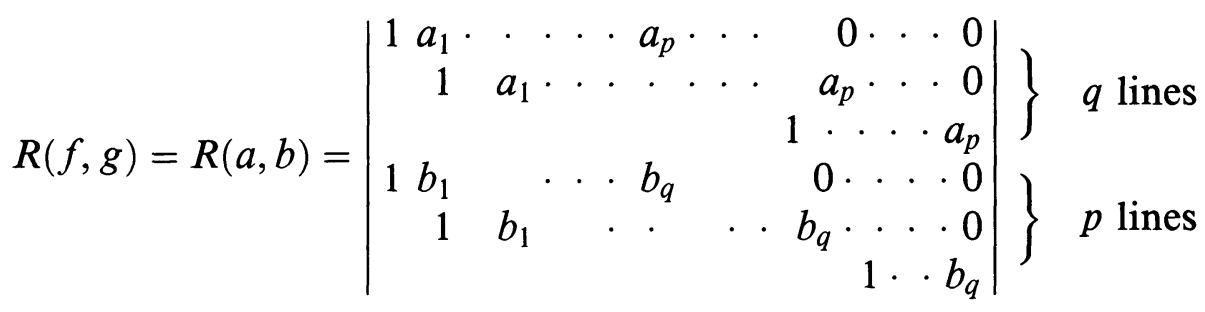

When $g=f^{\prime} / p$, then $D(f)=(f, g)$ is called the discriminant of the polynomial $f$ and the discriminant hypersurface $D_{p}=\left\{f \in \mathbf{C}^{p}, D(f)=\right.$ $0\}$ has occurred several times in Singularity Theory, since it can be identified to the discriminant of a versal deformatioin of the simple hypersurface singularity $A_{p-1}: x^{p}=0$, see for instance [1], [3], [9]. In 
particular, the fundamental group $\pi=\pi_{1}\left(C^{p} \backslash D_{p}\right)$ is the famous braid group [1] (with $p$ strings) and $\mathbf{C}^{p} \backslash D_{p}$ is in fact a $K(\pi, 1)$ space.

In this note we consider the analogous resultant hypersurface

$$
R_{p, q}=\left\{(f, g) \in \mathbf{C}^{p+q} ; R(f, g)=0\right\}
$$

and prove the following.

THEOREM. $\pi_{1}\left(\mathbf{C}^{p+q} \backslash R_{p, q}\right)=Z$.

Since $\mathbf{C}^{p} \backslash D_{p}$ can be regarded as a linear section of $\mathbf{C}^{p+q} \backslash R_{p, q}$, this theorem shows that by a nongeneric linear section the fundamental group may change drastically, in contrast with the case of generic section [4].

It is also interesting to note that the complements $F_{p, q}=\mathbf{C}^{p+q} \backslash R_{p, q}$ have already occurred in an important topological problem [7], going back to certain questions in Control Theory [2]. In short, consider the space of rational real functions of the form

$$
\phi=\frac{x^{n}+\alpha_{1} x^{n-1}+\cdots+\alpha_{n}}{x^{n}+\beta_{1} x^{n-1}+\cdots+\beta_{n}}
$$

with $\alpha_{i}, \beta_{j} \in R$ and the numerator and the denominator having no common root. Then $\phi$ induces a continuous map $P^{1}(\mathbf{C})=\mathbf{C} \cup\{\infty\} \rightarrow$ $\mathbf{C} \cup\{\infty\}=P^{1}(\mathbf{C})$ of degree $n$ and its restriction to the equator $R \cup$ $\{\infty\}=S^{1} \subset S^{2}=P^{1}(\mathbf{C})$ gives a map $S^{1} \rightarrow S^{1}$ having degree $r$ such that $-n \leq r \leq n$ and $n-r \equiv 0 \bmod 2$. Let $E_{n-r}$ denote the space of these mappings with $n$ and $r$ fixed, with the obvious topology. Then Segal has shown in [7] that $E_{n, r}$ is homeomorphic to $F_{p, q}$ with $p+q=n$ and $p-q=r$. He has also proved our Theorem in the special case $p=q$, by a method completely different from ours.

We derive our Theorem from some basic properties of the resultant hypersurface (which are also interesting in themselves) combined with a deep result of Lê-Saito [6] on the connectivity of the Milnor fiber of non-isolated singularity.

LEMMA 1. $R \in \mathbf{C}[a, b]$ is a weighted homogeneous polynomial of degree $p q$ with respect to the weights $\mathrm{wt}\left(a_{i}\right)=\mathrm{wt}\left(b_{i}\right)=i$.

Proof. Note that the polynomial $t \cdot f=x^{p}+t a_{1} x^{p-1}+\cdots+t^{p} a_{p}$ has as roots the elements $t x_{i}$, where $x_{i}$ are the roots of $f$, for any $t \in \mathbf{C}^{*}$. Then, using [5], p.137, we get $R(t \cdot f, t \cdot g)=\prod_{i, j}\left(t x_{i}-t y_{j}\right)=$ $t^{p q} \prod_{i, j}\left(x_{i}-y_{j}\right)=t^{p q} R(f, g)$, where $y_{j}$ are the roots of $g$. 
The key remark in the proof is that the resultant hypersurface has a smooth normalization $\nu$ which can be described explicitly as follows:

$$
\nu=\mathbf{C} \times \mathbf{C}^{p-1} \times \mathbf{C}^{q-1} \rightarrow R_{p, q} \subset \mathbf{C}^{p+q}
$$

$\nu(t, \alpha, \beta)=\left((x-t) f_{\alpha},(x-t) g_{\beta}\right)$, where $f_{\alpha}=x^{p-1}+\alpha_{1} x^{p-2}+\cdots+\alpha_{p-1}$, $g_{\beta}=x^{q-1}+\beta_{1} x^{q-2}+\beta_{1} x^{q-2}+\cdots+\beta_{q-1}$. Then $\nu$ is clearly surjective onto $R_{p, q}$ and the cardinal of a fiber $\nu^{-1}(f, g)$ is equal to the number of common roots of the equations $f=0, g=0$, counted without taking their multiplicities into account. Hence $\nu$ is a finite morphism which is generically one-to-one so that $\nu$ is indeed a normalization for $R_{p, q}$.

We use $\nu$ to investigate the singularities of the hypersurface $R_{p, q}$. To do this, we first compute the differential of $\nu$ at a point $\left(t_{0}, \alpha_{0}, \beta_{0}\right)$ :

$$
\begin{aligned}
& d \nu\left(t_{0}, \alpha_{0}, \beta_{0}\right)(t, \alpha, \beta) \\
& \quad=\left(\left(x-t_{0}\right)\left(f_{\alpha}-x^{p-1}\right)-t f_{\alpha_{0}},\left(x-t_{0}\right)\left(g_{\beta}-x^{q-1}\right)-t g_{\beta_{0}}\right) .
\end{aligned}
$$

Assume that $t_{0}$ is not a root for $f_{\alpha_{0}}$ and $g_{\beta_{0}}$ simultaneously. Then it follows that $d \nu\left(t_{0}, \alpha_{0}, \beta_{0}\right)$ is an injective linear map and its image (which is a hyperplane in the vector space $V$ of all the pairs $(A, B)$, with $A, B \in \mathbf{C}[x], \operatorname{deg} A \leq p-1, \operatorname{deg} B \leq q-1)$ is given by the equation

$$
f_{\alpha_{0}}\left(t_{0}\right) B\left(t_{0}\right)-g_{\beta_{0}}\left(t_{0}\right) A\left(t_{0}\right)=0 .
$$

Let $d(f, g)$ be the greatest common divisor of the polynomials $f$ and $g$. The above computation gives us the next

COROLlARY 2. The point $(f, g)$ is nonsingular on the hypersurface $R_{p, q}$ if and only if $\operatorname{deg} d(f, g)=1$.

Proof. Use the fact that a point $(f, g) \in R_{p, q}$ is nonsingular if and only if $\nu^{-1}(f, g)$ consists of one point, say $y$, and the corresponding germ $\nu:\left(\mathbf{C}^{p+q}, y\right) \rightarrow\left(R_{p, q},(f, g)\right)$ is an isomorphism.

We have also the more general result.

Proposition 3. Assume that $d(f, g)=\left(x-t_{1}\right) \ldots\left(x-t_{s}\right)$ is a product of $s$ linear distinct factors. Then the germ $\left(R_{p, q},(f, g)\right)$ consists of $s$ smooth hypersurface germs passing through $(f, g)$ with normal crossings.

Proof. In this case the fiber $\nu^{-1}(f, g)$ consists of $s$ points, say $y_{k}$ with $k=1, \ldots, s$. Moreover, the germs $\nu_{i}:\left(\mathbf{C}^{p+q-1}, y_{i}\right) \rightarrow\left(R_{p, q},(f, g)\right) \subset$ $\left(\mathbf{C}^{p+q},(f, g)\right)$ induced by $\nu$ are all imbeddings and $H_{i}=\operatorname{im}\left(\nu_{i}\right)$ are pre- 
cisely the (smooth) irreducible components of the germ $\left(R_{p, q},(f, g)\right)$. The corresponding tangent spaces are $T_{k}=T_{(f, g)} H_{k}: \bar{f}\left(t_{k}\right) B\left(t_{k}\right)-$ $\bar{g}\left(t_{k}\right) A\left(t_{k}\right)=0$ for $K-1, \ldots, s$ and $\bar{f}=f / d(f, g), \bar{g}=g / d(f, g)$. The condition of normal crossing in this case means that $\operatorname{codim}\left(\bigcap_{k=1, s} T_{k}\right)$ $=s$.

But this intersection corresponds to the kernel of the following linear map. $\quad T: V \simeq \mathbf{C}^{p+q} \rightarrow \mathbf{C}[x] /(d(f, g)) \simeq \mathbf{C}^{s}$ such that the $k$ th component of $T(A, B)$ is just the evaluation on $t_{k}$ of $(\bar{f} \cdot B-\bar{g} \cdot A)$, for $k=1, \ldots, s$. It is easy to check that $T$ is a surjective map and hence $\operatorname{codim}\left(\bigcap_{k=1, s} T_{k}\right)=\operatorname{codim}(\operatorname{ker} T)=s$.

COROLlARY 4. The hypersurface $R_{p, q}$ has only normal crossings singularities in codimension 1 and hence $\pi_{1}\left(\mathbf{C}^{p+q} \backslash R_{p, q}\right)=Z$.

Proof. The singularities of $R_{p, q}$ which are not normal crossings (as described in Proposition 3) lie in the image of the map

$$
\begin{gathered}
\tau: \mathbf{C} \times \mathbf{C}^{p-2} \times \mathbf{C}^{q-2} \rightarrow R_{p, q}, \\
\tau(t, \alpha, \beta)=\left((x-t)^{2} \widetilde{f}_{\alpha},(x-t)^{2} \widetilde{g}_{\beta}\right)
\end{gathered}
$$

with $\widetilde{f}_{\alpha}, \widetilde{g}_{\beta}$ having a meaning similar to $f_{\alpha}, g_{\beta}$. But $\operatorname{dim}(\operatorname{im} \tau) \leq p+q-$ $3=\operatorname{dim} R_{p, q}-2$ which proves the first assertion above. Next consider the fibration $F \rightarrow \mathbf{C}^{p+q} \backslash R_{p, q} \rightarrow \mathbf{C}^{*}$ with $F=F^{-1}(1)=\{(f, g) \in$ $\left.\mathrm{C}^{p+q} ; R(f, g)=1\right\}$. Using the weighted homogeneity of $R$ given by Lemma 1 , we can identify this fibration with the Milnor fibration of the hypersurface singularity $\left(R_{p, q},\left(x^{p}, y^{q}\right)\right)$. It follows by [6] that $\Pi_{1}(F)=0$ and hence we get an isomorphism

$$
R_{\#}=\prod_{1}\left(\mathbf{C}^{p+q} \backslash R_{p, q}\right) \rightarrow \prod_{1}\left(\mathbf{C}^{*}\right)=Z .
$$

This ends the proof of this corollary as well as giving a more precise version of our Theorem above.

REMARK 5. There is a natural $\mathbf{C}$-action on $\mathbf{C}^{p+q}$ leaving the resultant hypersurface $R_{p, q}$ invariant. Namely we define the translation of an element $(f, g)$ by the complex number $\lambda$ to be the element $\left(f^{\lambda}, g^{\lambda}\right)$ where

$$
f^{\lambda}=\prod_{i=1, p}\left(x-x_{i}-\lambda\right), \quad g^{\lambda}=\prod_{j=1, q}\left(x-y_{j}-\lambda\right)
$$


with $x_{i}$ (resp. $y_{j}$ ) being the roots of $f$ (resp. $g$ ). Since the hyperplane $a_{1}=0$ is clearly transversal to all the $C$-orbits, it follows that

$$
R_{p, q}=\bar{R}_{p, q} \times \mathrm{C} \quad \text { with } \bar{R}_{p, q}=R_{p, q} \cap\left\{a_{1}=0\right\} .
$$

The first non-trivial case of a resultant hypersurface is for $p=q=$ 2. Then $\bar{R}_{2,2}$ is just the Whitney umbrella $W: \bar{b}_{2}^{2}-b_{1}^{2} a_{2}=s$, with $\bar{b}_{2}=b_{2}-a_{2}$, called also a $D_{\infty}$-surface singularity for a pinch point. It follows that $\mathbf{C}^{4} \backslash R_{2,2}=\left(\mathbf{C}^{3} \backslash W\right) \times \mathbf{C}$ and the homotopy groups of $\mathbf{C}^{3} \backslash W$ can be derived from the Milnor fibration $F_{\infty} \rightarrow \mathbf{C}^{3} \backslash W \rightarrow \mathbf{C}^{*}$ associated to the $D_{\infty}$-singularity [8]. It is known that $F_{\infty}$ has the homotopy type of the 2-sphere $S^{2}$ and hence

$$
\prod_{k}\left(\mathbf{C}^{4} \backslash R_{2,2}\right)=\prod_{k}\left(S^{2}\right) \quad \text { for } k \geq 2 .
$$

In particular $\mathbf{C}^{4} \backslash R_{2,2}$ is not a $K(Z, 1)$ space, since $\Pi_{2}\left(\mathbf{C}^{4} \backslash R_{2,2}\right)=Z$.

\section{REFERENCES}

[1] E. Brieskorn Sur les groupes de tresses (d'aprés V. I. Arnold), Séminaire Bourbaki 1971/72, Exposées 400-417, p. 21-44, Lecture Notes in Mathematics 314, Springer 1973.

[2] R. Brockett, Some geometric questions in the theory of linear systems, IEEE Trans. of Automatic Control, bf21 (1976), 449-455

[3] A. Dimca and R. Rosianu, The Samuel stratification of the discriminant is Whitney regular, Geom. Dedicata, 17 (1984), 181-184.

[4] H. Hamm and D.-T. Le, Un théorème de Zariski du type de Lefschetz, Ann. Sci. Ec. Norm. Sup. 6 (1973), 317-366.

[5] S. Lang, Algebra, Addison-Wesley (1965), Reading, Massachusetts.

[6] D. T. Lê and K. Saito, The local $\prod_{1}$ of the complement of a hypersurface with normal crossings in codimension 1 is abelian, Ark. Mat., 22 (1984), 1-24.

[7] G. Segal, The topology of spaces of rational functions, Acta Math., 143 (1979), 39-72.

[8] D. Siersma, Isolated line singularities, Proc. Symp. Pure Math., 40 (1983) part 2, p. 485-496, Amer. Math. Soc., 1983.

[9] B. Teissier, The hunting of invariants in the geometry of discriminants, in Real and complex Singularities (Oslo, 1976), Sythoff and Noordhoff (1977), 566677.

Received April 29, 1988.

Central Washington University

ELLENSBURG, WA 98926 



\section{PACIFIC JOURNAL OF MATHEMATICS EDITORS}

\author{
V. S. VARADARAJAN \\ (Managing Editor) \\ University of California \\ Los Angeles, CA 90024-1555-05 \\ Herbert Clemens \\ University of Utah \\ Salt Lake City, UT 84112 \\ ThOMAs EnRIGHT \\ University of California, San Diego \\ La Jolla, CA 92093
}

R. FINN

Stanford University

Stanford, CA 94305

HeRmanN FlaschKa

University of Arizona

Tucson, AZ 85721

VAUGHAN F. R. Jones

University of California

Berkeley, CA 94720

SteVEn KerckHofF

Stanford University

Stanford, CA 94305

\author{
ROBION KIRBY \\ University of California \\ Berkeley, CA 94720 \\ C. C. MOORE \\ University of California \\ Berkeley, CA 94720 \\ HAROLd StaRK \\ University of California, San Diego \\ La Jolla, CA 92093
}

\section{ASSOCIATE EDITORS}
R. ARENS
E. F. BECKENBACH
B. H. NeUMANN
F. WoLF
K. YoshidA (1906-1982)
(1904-1989)

\section{SUPPORTING INSTITUTIONS}

\section{UNIVERSITY OF ARIZONA UNIVERSITY OF BRITISH COLUMBIA CALIFORNIA INSTITUTE OF TECHNOLOGY UNIVERSITY OF CALIFORNIA MONTANA STATE UNIVERSITY UNIVERSITY OF NEVADA, RENO NEW MEXICO STATE UNIVERSITY OREGON STATE UNIVERSITY}

\author{
UNIVERSITY OF OREGON \\ UNIVERSITY OF SOUTHERN CALIFORNIA \\ STANFORD UNIVERSITY \\ UNIVERSITY OF HAWAII \\ UNIVERSITY OF TOKYO \\ UNIVERSITY OF UTAH \\ WASHINGTON STATE UNIVERSITY \\ UNIVERSITY OF WASHINGTON
}

The Supporting Institutions listed above contribute to the cost of publication of this Journal, but they are not owners or publishers and have no responsibility for its content or policies.

Mathematical papers intended for publication in the Pacific Journal of Mathematics should be in typed form or offset-reproduced (not dittoed), double spaced with large margins. Please do not use built up fractions in the text of the manuscript. However, you may use them in the displayed equations. Underline Greek letters in red, German in green, and script in blue. The first paragraph must be capable of being used separately as a synopsis of the entire paper. In particular it should contain no bibliographic references. Please propose a heading for the odd numbered pages of less than 35 characters. Manuscripts, in triplicate, may be sent to any one of the editors. Please classify according to the scheme of Math. Reviews, Index to Vol. 39. Supply name and address of author to whom proofs should be sent. All other communications should be addressed to the managing editor, or Elaine Barth, University of California, Los Angeles, California 90024-1555-05.

There are page-charges associated with articles appearing in the Pacific Journal of Mathematics. These charges are expected to be paid by the author's University, Government Agency or Company. If the author or authors do not have access to such Institutional support these charges are waived. Single authors will receive 50 free reprints; joint authors will receive a total of 100 free reprints. Additional copies may be obtained at cost in multiples of 50 .

The Pacific Journal of Mathematics is issued monthly as of January 1966. Regular subscription rate: $\$ 190.00$ a year (6 Vols., 12 issues). Special rate: $\$ 95.00$ a year to individual members of supporting institutions.

Subscriptions, orders for numbers issued in the last three calendar years, and changes of address should be sent to Pacific Journal of Mathematics, P.O. Box 969, Carmel Valley, CA 93924, U.S.A. Old back numbers obtainable from Kraus Periodicals Co., Route 100, Millwood, NY 10546.

The Pacific Journal of Mathematics at P.O. Box 969, Carmel Valley, CA 93924 (ISSN 0030-8730) publishes 6 volumes per year. Second-class postage paid at Carmel Valley, California 93924, and additional mailing offices. Postmaster: send address changes to Pacific Journal of Mathematics, P.O. Box 969, Carmel Valley, CA 93924.

\section{PUBLISHED BY PACIFIC JOURNAL OF MATHEMATICS, A NON-PROFIT CORPORATION} Copyright (C) 1990 by Pacific Journal of Mathematics 


\section{Pacific Journal of Mathematics}

Vol. 142, No. $2 \quad$ February, 1990

Christopher J. Bishop, Bounded functions in the little Bloch space . . . . . 209

Lutz Bungart, Piecewise smooth approximations to $q$-plurisubharmonic

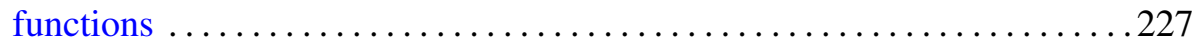

Donald John Charles Bures and Hong Sheng Yin, Outer conjugacy of

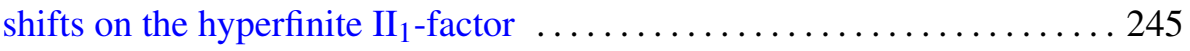

A. D. Raza Choudary, On the resultant hypersurface $\ldots \ldots \ldots \ldots \ldots 259$

Luis A. Cordero and Robert Wolak, Examples of foliations with foliated

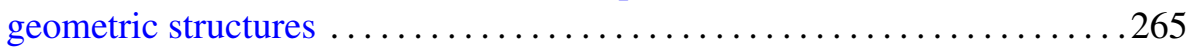

Peter J. Holden, Extension theorems for functions of vanishing mean

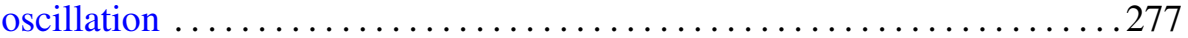

Detlef Müller, A geometric bound for maximal functions associated to convex bodies ........................................ 297

John R. Schulenberger, Time-harmonic solutions of some dissipative problems for Maxwell's equations in a three-dimensional half space . . . 313

Mark Andrew Smith and Barry Turett, Normal structure in Bochner

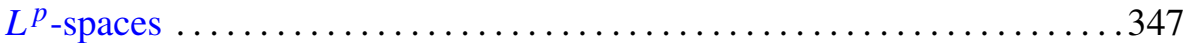

Jun-ichi Tanaka, Blaschke cocycles and generators ................... 357

R. Z. Yeh, Hyperholomorphic functions and higher order partial differential equations in the plane ................................ 379 